\title{
Emerging Approaches of Transcatheter Valve Repair/Insertion
}

\author{
Maurizio Taramasso, Micaela Cioni, Andrea Giacomini, Iassen Michev, Cosmo Godino, \\ Matteo Montorfano, Antonio Colombo, Ottavio Alfieri, and Francesco Maisano
}

\author{
Cardiothoracic Department, San Raffaele Scientific Institute, via Olgettina 60, 20122 Milan, Italy \\ Correspondence should be addressed to Maurizio Taramasso, m.taramasso@gmail.com
}

Received 8 March 2010; Revised 20 June 2010; Accepted 21 June 2010

Academic Editor: Ryuichi Morishita

Copyright (C 2010 Maurizio Taramasso et al. This is an open access article distributed under the Creative Commons Attribution License, which permits unrestricted use, distribution, and reproduction in any medium, provided the original work is properly cited.

Aortic stenosis (AS) and mitral regurgitation (MR) account for the majority of valvular diseases and their prevalence is increasing according to increased life expectancy. Surgical treatment is the gold standard, although operative risk may be high in some patients due to comorbidities and age. A large part of the patients at high surgical risk who could beneficiate of treatment are not referred to surgery. Therefore, there is a need of alternative and less invasive procedures.

\section{Introduction}

Valvular heart disease is nowadays a relevant cause of morbidity and mortality. Aortic stenosis (AS) and mitral regurgitation (MR) account for the majority of valvular diseases and their prevalence is increasing according to phenomenon of population ageing $[1,2]$.

Surgery (aortic valve replacement for the AS and mitral valve repair or replacement for MR) is the gold standard treatment and warrants good and reproducible clinical and functional outcomes in most patients, although operative risk may be high in some patients due to comorbidities and age. Several registries revealed that up to $50 \%$ of the patients with severe valvular disease, even if a surgical indication existed, are not referred to surgery and the main reasons of this are a high operative risk, multiple comorbidities and advanced age $[3,4]$. Thus, surgery is denied for a relevant number of patients who could beneficiate of it. Therefore, there is a need of alternative and less invasive procedures. The target of these novel minimal invasive techniques is to provide results similar to those of conventional surgery in terms of efficacy, safety, and durability. Over the past years several techniques for percutaneous repair and implantation have been developed. This paper provides an overview of these emerging approaches of transcatheter valve repair/implantation procedures.

\section{Percutaneous Aortic Valve Therapy}

Aortic stenosis is currently the most common valvular disease in the Western population, with a prevalence of $4.6 \%$ in adults $\geq 75$ years $[3,5]$. The need for aortic valve replacement (AVR) will continue to escalate according to the increase in life expectancy [6]. Surgical AVR has been performed since the early 1960s and is currently the standard treatment for patients with severe symptomatic AS, providing relief of symptoms and improving survival (survival has been shown to improve from $38 \%$ to $90 \%$ at 5 years following surgical AVR) and quality of life, even in the very elderly group [7-12]. Surgical AVR has an average operative mortality of $3 \%$ to $8 \%$, with an important variability primarily due to patient characteristics, comorbidities, and reduced left ventricular function $[7,8,13,14]$. Several scoring systems have been developed in order to help predict operative mortality, such as the logistic European System for Cardiac Operative Risk Evaluation (EuroSCORE) and the Society of Thoracic Surgeons (STS) score $[15,16]$.

Patients with high EuroSCORE or STS score are often denied surgery. The advent of transcatheter technologies may provide a desired alternative to medical management for these high-risk patients.

Moreover, the feasibility of the implantation of a percutaneous aortic valve using the TAVI techniques (valve-in-valve 


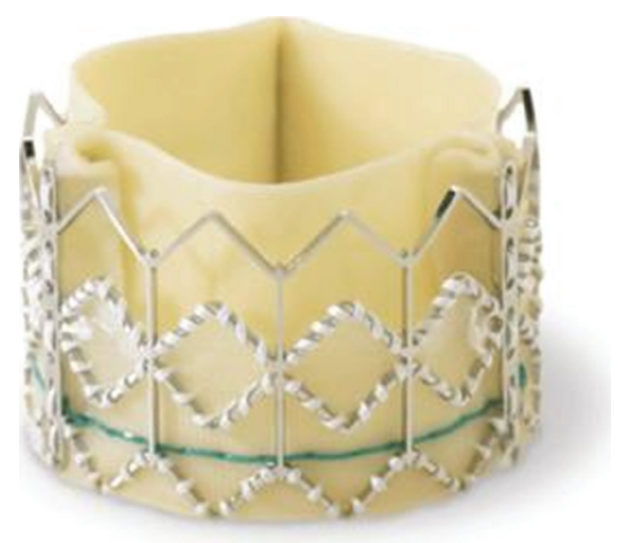

Figure 1: The Edwards-Sapien balloon-expandable prosthetic valve, constructed of a stainless-steel stent, bovine pericardial leaflets and a fabric sealing cuff.

concept) to treat patients with a degenerated bioprosthesis previously surgically implanted has been recently demonstrated $[17,18]$. In the future, TAVI approach will likely become an option not just for elderly or high-risk patients, but also for younger patients with the knowledge that a valvein-valve procedure can be performed if degeneration occurs. This could revolutionize the treatment of aortic valve disease.

\section{Current Techniques}

First human implantation of a balloon-expandable percutaneous aortic valve (AV) was performed in 2002 by Cribier et al. to treat a severe calcified AS in a 57-year-old man with prohibitive surgical risk [19]. Since then, thousands of patients have undergone this procedure worldwide, and at this time, eight years after this initial experience, transcatheter aortic valve implantation (TAVI) is a primary therapeutic modality for high-risk or technically inoperable patients with critical AS.

In November 2007, a committee of experts including members of EACTS and ESC defined a consensus position statement for TAVI procedures [20].

Two different devices are under clinical investigation and commonly used for TAVI.

3.1. Edwards-Sapien Prosthesis. The first device is the Edwards-Sapien valve (Edwards Lifescience, Inc., CA, USAFigure 1). It consists of three bovine pericardial leaflets mounted within a balloon-expandable stainless-steel stent. Current prosthesis sizes include 23 and $26 \mathrm{~mm}$. Current devices require either $22 \mathrm{~F}$ or $24 \mathrm{~F}$ (transfemoral) or $26 \mathrm{~F}$ (transapical) sheath for delivery [21].

The Edwards-Sapien valve was first implanted via the antegrade transseptal approach to the left atrium and passage through the mitral valve to reach the AV [19]. With this approach there is a high risk of anterior mitral valve leaflet injury, causing severe mitral regurgitation. Transfemoral retrograde approach has been shown to be safer and is now preferred [22-26]. Patients are usually placed under

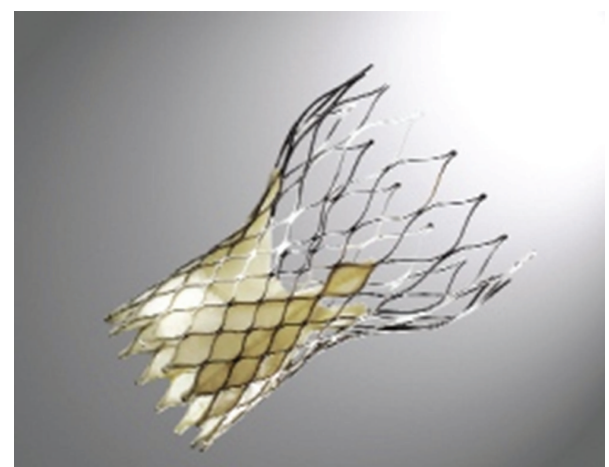

Figure 2: The CoreValve self-expandable prosthetic valve, constructed of a nitinol stent, pericardial leaflets, and sealing cuff.

general anesthesia with endotracheal intubation, although sedation and analgesia may be sufficient. After crossing the $\mathrm{AV}$, a balloon aortic valvuloplasty (BAV) is performed using standard techniques in order to predilate the stenotic valve. Simultaneous rapid right ventricular pacing using a temporary pacemaker (usually $180 \mathrm{beat} / \mathrm{min}$ ), decreasing cardiac output, is used to stabilize the balloon during the inflation. The percutaneous valve is then placed within the aortic annulus, and when its position seems to be optimal, it is released. Also the deployment of the valve is achieved under rapid pacing. For the larger introducers (22 F, 24 F) used with the Sapien valves, two 10 Fr Prostar closure devices are usually placed within the vessel before any introducer sheath is sited. Because of the large delivery system, a surgical cutdown and repair of the vascular access site are still often required [27].

Because of the large profile of the device, many patients with small or diseased iliofemoral arteries are not eligible for the procedure. The minimal vessel diameter required for sheath insertion in the transfemoral approach is 7 and $8 \mathrm{~mm}$ for the 22- and 24-F catheters, respectively, for the EdwardsSapien valve.

An alternative transapical antegrade approach has been proposed, with good initial results [28-30]. Through a left anterolateral minithoracotomy, with the patient under general anesthesia, the pericardium is opened over the apex. Temporary pacing wires are placed on the left ventricle (LV), the LV apex is punctured, and 2 pledgeted sutures are placed. A stiff wire is passed to the descending aorta, and BAV is performed. The percutaneous valve is then deployed. For the transapical approach, femoral access and cardiopulmonary bypass should be on standby, to consent a rapid surgical conversion in case of complications.

3.2. CoreValve Revalving System. The second device is the CoreValve Revalving System (Medtronic, Inc., MN, USAFigure 2), which consists in three porcine pericardial leaflets mounted in a self-expanding nitinol frame. The CoreValve is available in 26 and $29 \mathrm{~mm}$ sizes, going through an $18 \mathrm{~F}$ introducer, allowing smaller arterial diameters $(6 \mathrm{~mm})$ in respect to the delivery system of the Edwards-Sapien valve. The total length of the valve is $50 \mathrm{~mm}$. It has a specific design with a waist in the middle part. The lower part of 
the valve is designed to expand using high-radial forces. The middle part includes the leaflets and is constrained to avoid coronary occlusion, while the upper part enables fixation in the ascending aorta. The CoreValve is typically implanted retrograde from the femoral artery.

A transaxillary approach has been proposed for the selfexpandable valve and it has been used also with the balloonexpandable valve [31, 32].

Recently, for patients with "no-access options", also a transaortic approach through a ministernotomy access has been described $[33,34]$. The latest 3rd generation device enables performance of the procedure without rapid pacing $[21,24]$.

Whilst the Edwards system appears to have a greater requirement for native valve calcification in order to anchor the prosthesis, the CoreValve is self-expandable with a shape that seems less likely to embolize, even within a valve containing little calcium.

The positioning of the CoreValve is straightforward in theory; however, the self-expanding nature of the valve presents certain dynamism to the deployment process that remains, on occasion, challenging. An advantage of this device over the Edwards-Sapien valve, however, is that it is fully retrievable as long as the introducer catheter is not released from the valve. Once released, however, neither device is retrievable.

\section{Patient Selection}

4.1. Surgical Risk. TAVI is indicated in patients with pure or predominant severe AS, while the treatment of severe aortic regurgitation is still an off-label indication for TAVI. The most important issue in the selection of the candidates for TAVI is the analysis of the surgical risk and the evaluation of life expectancy. The decision-making process should involve a multidisciplinary team composed by cardiologists, cardiac surgeons, radiologists, and anesthesiologists. Physician's judgment in association with an assessment based on several surgical risks score (expected mortality $>20 \%$ with Logistic EuroSCORE and $>10 \%$ with STS score) is the key element to establish patients at high surgical risk. This approach considers also factors that are not covered in the scores but that may make surgery prohibitive, such as porcelain aorta, previous CABG with patent graft, liver cirrhosis, or neurological dysfunction. Age alone or simply refusal of surgical intervention is not sufficient for indication to TAVI instead of surgery. TAVI should not be performed in patients presenting with a life expectancy $<1$ year because of extracardiac comorbidities $[15,16,20,35]$.

4.2. Anatomical Considerations. Once defined the surgical risk, feasibility of the TAVI procedure and exclusion of contraindications should be assess.

Coronary angiography or CT scan should be performed to evaluate the anatomy of the coronary arteries. However, many of these patients have calcified coronary disease, limiting the value of CT scan. In case of need of revascularization, the chronology and the modality of interventions should be individualized based on the clinical status of the single patients.

The correct sizing of the AV is the critical step to establish the feasibility of the TAVI and to minimize the risk of paravalvular leak or prosthesis migration after the deployment. A gold standard method of measurement has not been yet established. Echocardiography and CT scan are both used [36-40].

The evaluation of the state of the peripheral access (size, tortuosity, and calcification) is obtained by angiography or CT scan $[20,41]$.

The most important technical contraindications for TAVI are the inadequacy of the aortic annulus $(<18 \mathrm{~mm}$ or $>25 \mathrm{~mm}$ for balloon-expandable prosthesis and $<20 \mathrm{~mm}$ or $>27 \mathrm{~mm}$ for self-expandable), presence of asymmetric valvular calcification (because of the high risk of compression of the coronary arteries), an ascending aortic dimension $>45 \mathrm{~mm}$ at sinotubular junction for the self-expandable valve and the presence of LV thrombosis [20,23].

The choice of the correct approach (transfemoral or transapical) should be discussed according to the patient condition and local expertise. Specific contraindications for transfemoral approach include inadequacy of femoroiliac arteries (severe calcification, tortuosity, or small diameter, according to the device used or previous aortofemoral bypass), transverse ascending aorta for the balloonexpandable device, and adverse aortic condition (severe angulation, atheroma of the arch, and aneurysm of abdominal aorta with protruding mural thrombus). Contraindications for transapical approach are previous LV surgery (such as Dor procedure), severe respiratory insufficiency, not reachable LV apex through thoracotomy, and calcified pericardium [20].

In patients presenting with an estimated extreme clinical risk or because of anatomical inadequacy for TAVI, a BAV procedure may be useful as a bridge to subsequent percutaneous implantation or as palliation. No survival benefit has been showed after BAV [1-3, 42].

\section{Results}

Procedural success exceeds $90 \%$ in experienced centers. Mortality at 30-days ranges from $5 \%$ to $18 \%$ [22-26, $43-$ $45]$. The 30 day mortality reported in the SOURCE Registry, which was designed to assess the initial clinical results of the Edwards-Sapien valve in consecutive high-risk patients in Europe, was6.3\% in TF patients and $10.3 \%$ in TA patients $[46,47]$. The recently published Canadian experience with the Sapien valve reported an overall 30-day mortality of $10.4 \%$ (9.5\% for TF approach and $11.3 \%$ for TA approach) and a mortality rate at a mean followup of 8 months of $22.1 \%$ [44].

Incidence of stroke is $1.7 \%-2.5 \%$ and it seems to be similar for both procedural approaches $[44,46]$.

The periprocedural death observed with the CoreValve Revalving System is similar [43].

Vascular complications remain a significant cause of mortality and morbidity (incidence $10 \%-15 \%$ ) [23, 44-46], also if in the SOURCE Registry this type of complication was 
proved to be no longer a predictor of $<30$-day mortality in the transfemoral approach [46]. Acute myocardial infarction occurs in $2 \%-5 \%$ [46]. Coronary obstruction and prosthesis embolization are rare $(<1 \%)[20,24,26,48]$. Mildto-moderate AR, without hemodynamic impairment, is observed in about $50 \%$ of the patients, mostly para-valvular. Significant AR occurs in 2\%-5\% [24, 26, 43]. Finally, AV block occurs in 4\%-10\%, necessitating pacemaker implantation in up to $24 \%$ with self-expandable device [49-53]. Left bundle-branch block with left-axis deviation, interventricular septal dimension $>17 \mathrm{~mm}$, and noncoronary cusp thickness $>8 \mathrm{~mm}$ were identified as predictors of AV block and need of permanent pacemaker following placement of self-expandable prosthesis [54].

\section{Our 2-Year Experience with TAVI in High-Risk Surgical Candidates}

From November 2007, 137 patients with severe aortic stenosis underwent TAVI at our Institution, 64 females with mean age $79 \pm 7$ years. Peak and mean aortic gradients were 88.2 $\pm 25.4 \mathrm{mmHg}$ and $53.9 \pm 15.7 \mathrm{mmHg}$, respectively. Mean Logistic EuroSCORE and STS-PROM score were $26.3 \pm 16$ and $7 \pm 4.9$, respectively. Patients had multiple comorbidities (Charlson score $6 \pm 1.7$ ). Baseline characteristics of the patients are shown in Table 1.

An Edwards-Sapien valve was implanted in 79 patients (61 transfemoral, 15 transapical; and 3 transaxillary); a CoreValve was implanted in 58 patients (46 transfemoral and 12 transaxillary). Procedural success rate was $99.2 \%$ (1 acute aortic dissection requiring emergent surgery). Hospital mortality (30 days) was 3\%. Postoperative complications included vascular lesions (62 patients), renal failure (10 patients), need for PM (38 patients), moderate to-severeaortic regurgitation (14 patients), and cerebrovascular event (6 patients). Mean length of stay was $9 \pm 9.8$ days (range 2 -to68 days) (see Table 2). Followup was $100 \%$ complete (mean 6 \pm 4 months). Actuarial 6-month survival was $89 \% \pm 5 \%$ for the combined experience and it was $73 \% \pm 16 \%, 100 \%$, and $91 \% \pm 4 \%$ for the transapical, transaxillary and transfemoral approaches, respectively (Tables 2 and 3 ).

\section{Percutaneous Mitral Procedures for the Treatment of Mitral Regurgitation}

The development and evaluation of mitral valve (MV) repair technologies represents an emerging challenge. Currently, several percutaneous approaches for the treatment of MR are in early clinical use or undergoing preclinical investigation. Percutaneous repair of the MV has many differences compared to TAVI procedures, in consideration of the different mechanisms that can lead to MR (variable annular dilatation, abnormal leaflet coaptation, abnormal chordal structure, among others). One or more of the elements of the MV apparatus may be involved according to the etiology of the MR and the patient population may be very heterogeneous for age and comorbidities [55].

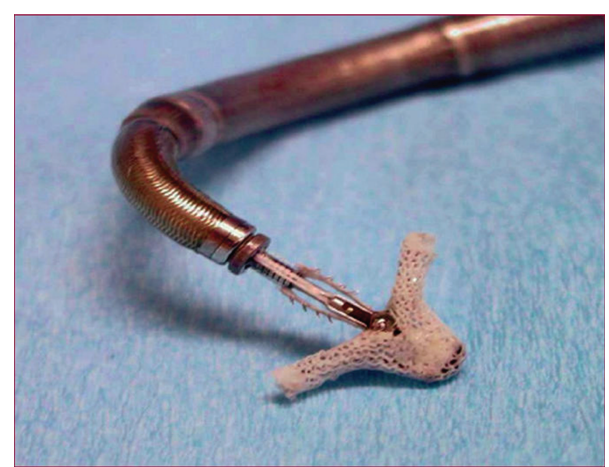

FIGURE 3: The Mitraclip device is a two-armed, polyester-covered, fixation device. Each arm has an opposing gripper that aids the leaflets in the clip by means of multipronged friction element.

The most advanced percutaneous MV repair procedure is the Alfieri edge-to-edge repair using the Evalve Percutaneous Mitral Repair System, also known as MitraClip device (Evalve, Inc., CA, USA-Figure 3). The Alfieri repair consists in suturing the free edge of the anterior mitral leaflet to the free edge of the posterior leaflet at the site of the regurgitation. The result is a double-orifice valve with improved leaflet coaptation. This surgical procedure has proven early efficacy and durability in various anatomic and functional lesions [56-58]. The Mitraclip system reproduces the surgical procedure using a clip to join the free edges of the opposing leaflets [59]. This procedure involves transseptal cannulation of the left atrium and positioning the delivery system perpendicular to the MV. Under TEE guidance, the clip is placed to appose the two mitral leaflets, creating a double-orifice valve. The reduction of the MR severity is real-time assessed and, if necessary, it may be repositioned to reduce MR further. The operator should be familiar with echo imaging and a close collaboration between the operator and the echocardiographist is mandatory to run the procedure safely and efficiently. Live 3D echocardiography is very helpful particularly for clip orientation and alignment on the coaptation line. Final echo assessment should be done under vasoconstrictors. When the result is satisfactory, the clip is deployed and the delivery system is removed. In case of persistent significant MR $(>2+/ 4+)$, a second clip may be placed.

Recently, the feasibility of the procedure using conscious sedation has been reported in [60].

\section{Patient Selection}

Patient selection is fundamental for the efficacy of the procedure. Indications for the Mitraclip are still preliminary and will continue to evolve as the techniques and technologies will prove efficacy and safety. The best indication for the endovascular edge-to-edge is given in those patients with severe degree of mitral regurgitation and with symptoms that are at high risk for surgery. From a pure technical standpoint, the procedure is feasible only in a subgroup of patients 
TABLE 1: Clinical characteristics of patients presenting for transcatheter aortic valve implantation.

\begin{tabular}{|c|c|c|c|c|}
\hline & Transfemoral & Transapical & Transaxillary & $P$ value \\
\hline Patients & 107 & 15 & 15 & \\
\hline Edwards-Sapien, $n(\%)$ & $61(57)$ & $15(100)$ & $3(20)$ & $<.0001$ \\
\hline CoreValve, $n(\%)$ & $46(43)$ & & $12(80)$ & $<.0001$ \\
\hline Age (years) & $79.7 \pm 7$ & $78.8 \pm 6.5$ & $78.7 \pm 5$ & .794 \\
\hline Male, $n(\%)$ & $56(52)$ & $5(33)$ & $12(80)$ & .034 \\
\hline Diabetes, $n(\%)$ & $31(29)$ & $4(26.7)$ & $5(33)$ & .917 \\
\hline Chronic kidney disease, $n(\%)$ & $39(36.4)$ & $5(33)$ & $7(46.7)$ & .706 \\
\hline Porcelain aorta, $n(\%)$ & $17(15.9)$ & $14(93.3)$ & $7(46.7)$ & $<.0001$ \\
\hline $\mathrm{COPD}, n(\%)$ & $46(43)$ & $6(40)$ & $11(73)$ & .077 \\
\hline Previous myocardial infarction, $n(\%)$ & $29(27)$ & $5(33)$ & $6(40)$ & .549 \\
\hline Cerebrovascular disease, $n(\%)$ & $20(18.7)$ & $8(53)$ & $3(20)$ & .011 \\
\hline Peripheral vascular disease, $n(\%)$ & $26(24.3)$ & $10(67.7)$ & $12(80)$ & $<.0001$ \\
\hline NYHA functional class III-IV, $n(\%)$ & $75(70)$ & $11(73.3)$ & $9(60)$ & .685 \\
\hline Logistic EuroSCORE, mean \pm SD & $26.6 \pm 16$ & $32.2 \pm 23$ & $28.6 \pm 14$ & .477 \\
\hline STS-PROM score, mean \pm SD & $7 \pm 4.9$ & $8.3 \pm 4.2$ & $6.9 \pm 2.8$ & 602 \\
\hline Mean aortic gradient $(\mathrm{mmHg})$, mean $\pm \mathrm{SD}$ & $54 \pm 17.2$ & $44.7 \pm 18$ & $47.7 \pm 14.9$ & .074 \\
\hline $\operatorname{LVEF}(\%)$, mean $\pm \mathrm{SD}$ & $50.8 \pm 12.9$ & $50 \pm 12.5$ & $52.8 \pm 11$ & .814 \\
\hline
\end{tabular}

COPD: chronic obstructive pulmonary disease; NYHA: New York Heart Association; LVEF: left ventricle ejection fraction.

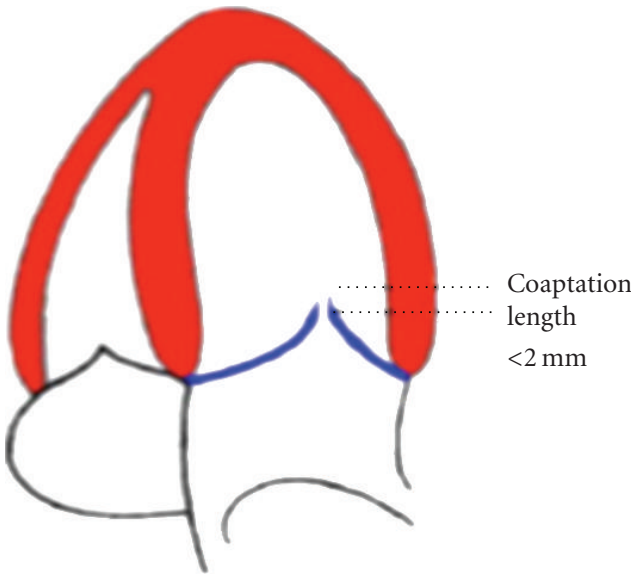

(a)

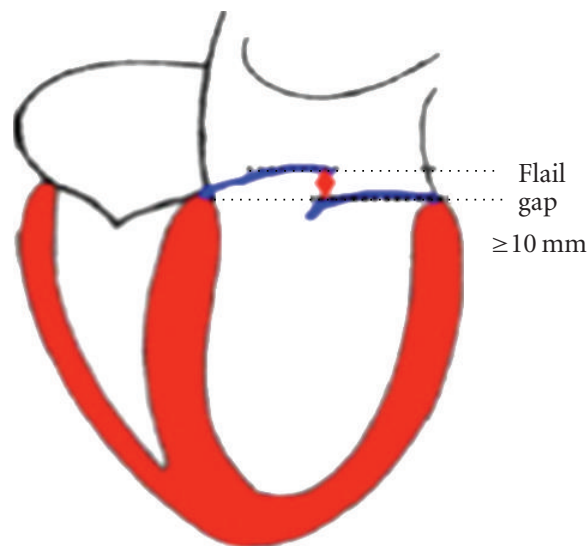

(c)

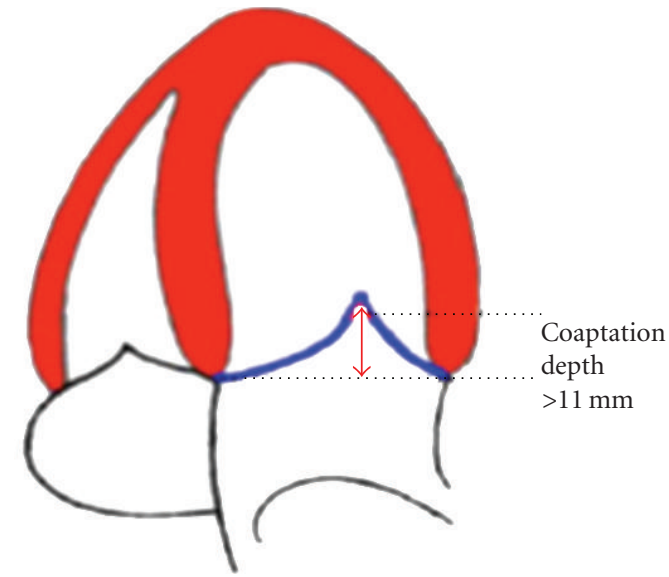

(b)

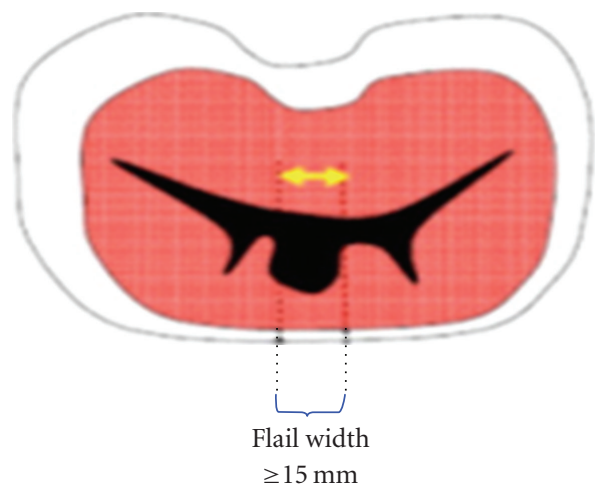

(d)

Figure 4: Anatomical exclusion criteria for the percutaneous edge-to-edge repair. 
TABLe 2: Procedural and in-hospital results of patients submitted to transfemoral TAVI approach in our Institution.

\begin{tabular}{lc}
\hline Patients $(n)$ & 107 \\
Hospital stay, days (mean \pm SD) & $9.5 \pm 1.4$ \\
Procedural success, $n(\%)$ & $100(93.5)$ \\
Vascular complications, $n(\%)$ & $31(29)$ \\
Need for permanent pacemaker, $n(\%)$ & $19(17.8)$ \\
Neurological event, $n(\%)$ & $3(2.8)$ \\
Acute renal failure requiring CVVH, $n(\%)$ & $5(4.7)$ \\
\hline 30-day clinical outcomes & \\
$\quad$ Death, $n(\%)$ & $1(0.9)$ \\
Cardiac death, $n(\%)$ & 0 \\
$\quad$ LVEF, $n(\%)$ & $52.6 \pm 11.5$ \\
\hline Six months cumulative clinical outcomes & $12(12.2)$ \\
$\quad$ Death, $n(\%)$ & $2(2.0)$ \\
Cardiac death, $n(\%)$ & $53.22 \pm 9.1$ \\
$\quad$ LVEF $(\%)$, mean \pm SD &
\end{tabular}

SD: standard deviation; CVVH: continuous veno-venous hemofiltration; LVEF: left ventricle ejection fraction.

with specific anatomical characteristics and this makes the eligibility limited (see Figure 4).

The first step in the screening process to select patients who could be eligible for the procedure is transthoracic echocardiography, especially with regard to the parasternal short-axis view of the mitral valve and origin of MR jet(s). The main eligibility criterion is jet location.

Definitive patient selection is done by transesophageal echocardiography. Mitral regurgitation should originate from the middle of the valve (from A2-P2 segments). The mechanism of regurgitation can be either a prolapse or a restricted motion not related to rheumatic disease. The discontinuation between the two leaflets at the site of regurgitation should be minimal and the annular dilatation and/or calcification should be absent or non relevant. In case of prolapse, the jet width should be less than $15 \mathrm{~mm}$, and the flail gap less than $10 \mathrm{~mm}$. In case of functional $\mathrm{MR}$, the jet width should be again less than $15 \mathrm{~mm}$, and the coaptation depth ideally should be less than $10 \mathrm{~mm}$, with the leaflets having a minimal residual coaptation [61-63].

\section{Results}

The results phase I of the multicenter prospective trial EVEREST (endovascular valve edge-to-edge repair study), including 107 patients with central MR (21\% with pure functional MR) who were eligible for surgical MV repair showed a periprocedural incidence of major events of 9\%, including 1 nonprocedural death. Freedom from clip embolization was $100 \%$. Procedural success was achieved in $74 \%$ of the patients, and $64 \%$ presented MR of $\leq 1+$ at discharge. Followup data showed that surgical option after percutaneous repair was preserved (32 patients had mitral valve surgery during the 3.2 years after clip procedures; in case of planned mitral repair, successful repair was obtained in $84 \%$ ) [64].
Among the successfully treated patients, freedom from death, mitral valve surgery, and $\mathrm{MR}>2+$ at 12 months were $66 \%$. Overall survival was $90.1 \%$, at 3 years. No differences were observed in terms of acute results and durability between patients with degenerative and functional MR [64].

The results of phase II of the study (EVEREST II), which compared standard surgical repair to percutaneous edge-to-edge mitral repair (randomization 2: 1 MitraClip to surgery), showed an incidence of major adverse events at 30 days (death, stroke, reoperation of MV, urgent/emergent cardiovascular surgery, myocardial infarction, renal failure, deep-wound infection, ventilation $>48$ hours, new onset permanent atrial fibrillation, septicemia, gastrointestinal complication requiring surgery, and transfusions $\geq 2$ units) of $9.6 \%$ for the clip and of $57 \%$ for surgical MV repair. Clinical success rate (freedom from death, MV surgery or reoperation for MV dysfunction, and MR $>2+$ ) at 12 months was $72 \%$ for the clip and $88 \%$ for surgical MV repair [65]. These results confirmed that the MitraClip procedure is a safe and effective therapeutic option for selected patients with significant MR.

\section{Our Initial Experience in High-Risk Patients}

In our Institution, 28 patients with severe MR have been treated using the Mitraclip. 22 patients had functional MR (FMR) and 6 patients had degenerative MR. Procedures were performed under general anesthesia, using live $3 \mathrm{D}$ transesophageal echocardiography. Mean age was $67.9 \pm 14.4$ years and mean $\mathrm{EF}$ was 35\% $\pm 20 \%(25 \% \pm 7 \%$ in $\mathrm{FMR}$ patients). All patients had severe central MR, dilated ventricles (mean DTD $67 \pm 6 \mathrm{~mm}$ ), and pulmonary hypertension (PAPs was $45 \pm 21 \mathrm{mmHg}$ ). Mean logistic EuroSCORE was $23.9 \pm 15.5$. In 17 patients there was the need of a second clip. Median stay in the ICU and in the general ward was 1 and 5 days, respectively. Postprocedural course was complicated by low cardiac output requiring inotropes in 6 patients $(21.4 \%)$, acute renal insufficiency in 3 patients $(10.7 \%)$, hemopericardium in 1 patient $(3.5 \%)$, need of IABP in 2 patients $(7.1 \%)$, and need of hemotransfusions in 3 patients $(10.7 \%)$. At discharge, 2 patients $(7.1 \%)$ had no MR $(0+/ 4+)$, 21 patients $(75 \%)$ had mild $(1+/ 4+) \mathrm{MR}$, and 5 patients $(17.8 \%)$ had moderate $(2+/ 4+)$ MR.

\section{Other Percutaneous MV Repair Procedures}

Several alternative percutaneous procedures for the treatment of the MV are being evaluated in preclinical studies.

The coronary sinus annuloplasty is based on the close anatomical relation of the coronary sinus with the posterior mitral annulus, and several devices exist for this approach: the aim is to place devices in the coronary sinus to push against the posterior portion of mitral annulus, in order to improve the coaptation of the leaflets. Although success in animals has been observed, human trials have presented more difficulties, likely because often the coronary sinus, which is an atrial structure, is not in the same plane as the mitral annulus. Moreover, the circumflex coronary artery 
TABLE 3: Procedural and in-hospital results of patients submitted to trans-apical and trans-axillary TAVI Approach in our Institution.

\begin{tabular}{lcc}
\hline & Trans-apical & Trans-axillary \\
\hline Patients $(n)$ & 15 & 15 \\
Hospital stay (days), mean \pm SD & $15.8 \pm 4.8$ & $8.7 \pm 1$ \\
Procedural success, $n$ (\%) & $13(86.6)$ & $14(93.3)$ \\
Need for permanent pacemaker, $n(\%)$ & $3(20)$ & $1(6.7)$ \\
Neurological events, $n$ (\%) & $1(6.7)$ & $1(6.7)$ \\
Acute renal failure requiring CVVH, $n(\%)$ & $4(26.6)$ & $2(13.3)$ \\
\hline 30-day clinical outcome & & 0 \\
Death, $n$ (\%) & $2(13.3)$ & 0 \\
Cardiac death, $n(\%)$ & $2(13.3)$ & $52.73 \pm 10.1$ \\
LVEF $(\%)$, mean \pm SD & $49.67 \pm 10.4$ & $2(18.2)$ \\
Six-month cumulative clinical outcome & & $1(9.1)$ \\
Death, $n$ (\%) & $4(26.6)$ & $60.23 \pm 3.45$ \\
Cardiac death, $n$ (\%) & $4(26.6)$ & $56.22 \pm 4.12$ \\
LVEF $(\%)$, mean \pm SD & & \\
\hline
\end{tabular}

SD: standard deviation; CVVH: continuous venovenous hemofiltration; LVEF: left ventricle ejection fraction.

or its branches may lie between the mitral annulus and the coronary sinus, and the distance between the coronary sinus and the posterior mitral annulus increases with chronic ischemic MR because of the ongoing remodeling process [66-68].

The most promising coronary sinus annuloplasty device is the CARILLON Mitral Contour System (Cardiac Dimensions, Inc., Kikland, Wash), which uses 2 self-expanding nitinol anchors connected by a wire: the distal coronary sinus anchor is deployed, then manual tension is applied to the connecting wire and the proximal anchor is deployed, obtaining a shortening of the mitral annular dimension. The tension on the device can be adjusted before the final release. The multicenter AMADEUS trial suggested an acute reduction in MR by a mean of 1 grade with the modified CARILLON XE device $[69,70]$.

Other techniques are based on the concept of moving the ventricle, rather than the annulus, to increase leaflet coaptation and eliminate functional MR. The Coapsys device (Myocor, Inc., MN, USA) employs a transventricular splint with pads on the outer surface of the left ventricle. In an open chest, this can be placed without cardiopulmonary bypass under direct echocardiographic guidance. Pads attached to each end of the splint are tightened to pull the ventricle into the region of the papillary muscles and also to move the posterior leaflet to better coapt with the anterior leaflet. Initial studies with the open-chest Coapsys system showed encouraging results [71-73].

The i-Coapsys device performs the same role but can be delivered in a minimally invasive procedure with fluoroscopic guidance [74].

Another field of application of percutaneous procedures for MR is the correction of a paravalvular leak following surgical MV replacement. When the periprosthetic leak is haemodynamically relevant, a percutaneous treatment may offer an alternative to the redo surgery in high-risk patients. Several different types of devices that have not been specifically designed for this purpose may be used (usually coils for very small defects, patent ductus devices for medium defects and atrial septal occluders for large defects). Results of transcatheter mitral paravalvular leak have achieved variable success rates, with a reported initial success rate of $60 \%$ to $90 \%$ and a need for repeat intervention of about $40 \%$ $[21,75-77]$.

The use of advanced image guidance with 3D echocardiography could enhance the technical success rate. The most important limitation remains the use of preexisting non specific devices.

\section{Limitations and Potential of Percutaneous Treatment of Heart Valve Disease}

With regard to TAVI, the pending questions concern mainly safety and long-term durability. Using it in patients who are good surgical candidates seems to be still premature. Thus, TAVI should currently be restricted to patients at high surgical risk or with contraindications for conventional surgery. The emerging concept of valve-in-valve may provide a feasible treatment option if and when currently implanted percutaneous aortic valves deteriorate. Moreover, with the advent of TAVI procedures, a degenerated bioprosthesis can now be replaced less invasively and perhaps with less risk using the transcatheter valve implantation techniques. Therefore, current guidelines for choosing the type of valve prosthesis may indeed require a revision.

With regard to MV repair using the Mitraclip, the surgical experience with Alfieri edge-to-edge technique indicates that significant MR recurs if the procedure is not associated to an annuloplasty (need for reoperation $30 \%$ at 5 years), especially in presence of a dilated mitral annulus [78-80], so the long-term results of this technique have still to be evaluated.

Percutaneous MV repair is attractive and should be considered in all patients with functional MR (ischemic or dilatative) at high surgical risk due to advanced age, 
concomitant comorbidities, or advanced heart failure, especially in presence of depressed EF, right ventricular dysfunction, or severe pulmonary hypertension. The main obstacles to the extension of this technique in high-risk patients are the limited anatomical eligibility and the long learning curve for the operators.

Another emerging field of application of percutaneous MV repair is the correction of simple degenerative MR in young patients. The goal of modern MV valve surgery, in fact, is to obtain excellent long-term results using an approach as little as possible invasive, such as miniinvasive or robotic surgery. The main purpose is the attempt to totally neutralize the disease, obtaining a survival and a quality of life comparable to an age-matched population. If the operation is performed by conventional surgery, for example, in a young female patient, the disease cannot be considered neutralized, because of the persistence of the scar: neutralizing the disease concerns also this aspect. This consideration may justify the use of percutaneous MV repair in young patients with simple MV prolapse, providing that percutaneous edge-to-edge does not preclude surgical mitral repair in case of failure of the percutaneous repair [81, 82]. As long as the percutaneous procedure is safe, even if success rate is lower than that of surgery, patients with failed percutaneous repairs are still candidates for surgical repair. Therefore, transcatheter therapy may temporarily delay or avoid the need for surgical intervention.

\section{Conclusions}

Transcatheter aortic and mitral valve procedures are evolving very rapidly and are currently a therapeutic modality for the patients with severe valvular disease who are unsuitable for surgery because of technical/anatomical issues or too high-estimated surgical risk. Several clinical trials, including randomized studies between surgical and percutaneous treatment, are currently ongoing and in the near future the indications for these procedures likely will be extended to patients who are good candidates for surgery.

\section{References}

[1] A. Vahanian, H. Baumgartner, J. Bax, et al., "Task force on the management of valvular hearth disease of the European Society of Cardiology; ESC committee for practice guidelines. Guidelines on the management of valvular heart disease: the task force on the management of valvular heart disease of the European Society of Cardiology," European Heart Journal, vol. 28, pp. 230-268, 2007.

[2] R. O. Bonow, B. A. Carabello, K. Chatterjee, et al., "2006 Writing Committee Members; American College of Cardiology/American Heart Association Task Force. 2008 Focused update incorporated into the ACC/AHA 2006 guidelines for the management of patients with valvular heart disease: a report of the American College of Cardiology/American Heart Association Task Force on Practice Guidelines (Writing Committee to Revise the 1998 Guidelines for the Management of Patients With Valvular Heart Disease): endorsed by the Society of Cardiovascular Anesthesiologists, Society for Cardiovascular Angiography and Interventions, and Society of Thoracic Surgeons," Circulation, vol. 118, no. 15, pp. e523e661, 2008.

[3] B. Iung, G. Baron, E. G. Butchart et al., "A prospective survey of patients with valvular heart disease in Europe. The Euro Heart Survey on valvular heart disease," European Heart Journal, vol. 24, no. 13, pp. 1231-1243, 2003.

[4] M. Mirabel, B. Iung, G. Baron et al., "What are the characteristics of patients with severe, symptomatic, mitral regurgitation who are denied surgery?" European Heart Journal, vol. 28, no. 11, pp. 1358-1365, 2007.

[5] V. T. Nkomo, J. M. Gardin, T. N. Skelton, J. S. Gottdiener, C. G. Scott, and M. Enriquez-Sarano, "Burden of valvular heart diseases: a population-based study," Lancet, vol. 368, no. 9540, pp. 1005-1011, 2006.

[6] US Census Bureau, United States Census 2000, Washington, DC, USA, US Census Bureau, 2001.

[7] A. T. Culliford, A. C. Galloway, S. B. Colvin et al., "Aortic valve replacement for aortic stenosis in persons aged 80 years and over," American Journal of Cardiology, vol. 67, no. 15, pp. 12561260, 1991.

[8] P. Kvidal, R. Bergstrom, L.-G. Horte, and E. Stahle, "Observed and relative survival after aortic valve replacement," Journal of the American College of Cardiology, vol. 35, no. 3, pp. 747-756, 2000.

[9] H. M. Connolly, J. K. Oh, H. V. Schaff et al., "Severe aortic stenosis with low transvalvular gradient and severe left: ventricular dysfunction: result of aortic valve replacement in 52 patients," Circulation, vol. 101, no. 16, pp. 1940-1946, 2000.

[10] A. Sedrakyan, P. Hebert, V. Vaccarino et al., "Quality of life after aortic valve replacement with tissue and mechanical implants," Journal of Thoracic and Cardiovascular Surgery, vol. 128, no. 2, pp. 266-272, 2004.

[11] C. H. Huber, V. Goeber, P. Berdat, T. Carrel, and F. Eckstein, "Benefits of cardiac surgery in octogenarians-a postoperative quality of life assessment," European Journal of CardioThoracic Surgery, vol. 31, no. 6, pp. 1099-1105, 2007.

[12] M. Vicchio, A. Della Corte, L. S. De Santo et al., "Tissue versus mechanical prostheses: quality of life in octogenarians," Annals of Thoracic Surgery, vol. 85, no. 4, pp. 1290-1295, 2008.

[13] B. C. Astor, R. G. Kaczmarek, B. Hefflin, and W. R. Daley, "Mortality after aortic valve replacement: results from a nationally representative database," Annals of Thoracic Surgery, vol. 70, no. 6, pp. 1939-1945, 2000.

[14] L. H. Burr, W. R. E. Jamieson, A. I. Munro, R. T. Miyagishima, and E. Germann, "Porcine bioprostheses in the elderly: clinical performance by age groups and valve positions," Annals of Thoracic Surgery, vol. 60, no. 2, pp. S264-S269, 1995.

[15] F. Roques, P. Michel, A. R. Goldstone, and S. A. M. Nashef, "The logistic EuroSCORE," European Heart Journal, vol. 24, no. 9, pp. 881-882, 2003.

[16] F. H. Edwards, F. L. Grover, A. L. W. Shroyer, M. Schwartz, and J. Bero, "The Society of Thoracic Surgeons National Cardiac Surgery Database: current risk assessment," Annals of Thoracic Surgery, vol. 63, no. 3, pp. 903-908, 1997.

[17] T. Walther, V. Falk, T. Dewey et al., "Valve-in-a-valve concept for transcatheter minimally invasive repeat xenograft implantation," Journal of the American College of Cardiology, vol. 50, no. 1, pp. 56-60, 2007.

[18] P. Wenaweser, L. Buellesfeld, U. Gerckens, and E. Grube, "Percutaneous aortic valve replacement for severe aortic regurgitation in degenerated bioprosthesis: the first valve in valve procedure using the CoreValve revalving system," Catheterization and Cardiovascular Interventions, vol. 70, no. 5, pp. 760-764, 2007. 
[19] A. Cribier, H. Eltchaninoff, A. Bash et al., "Percutaneous transcatheter implantation of an aortic valve prosthesis for calcific aortic stenosis: first human case description," Circulation, vol. 106, no. 24, pp. 3006-3008, 2002.

[20] A. Vahanian, O. R. Alfieri, N. Al-Attar et al., "Transcatheter valve implantation for patients with aortic stenosis: a position statement from the European Association of Cardio-Thoracic Surgery (EACTS) and the European Society of Cardiology (ESC), in collaboration with the European Association of Percutaneous Cardiovascular Interventions (EAPCI)," European Journal of Cardio-Thoracic Surgery, vol. 34, no. 1, pp. 1-8, 2008.

[21] L. F. Tops, S. R. Kapadia, E. M. Tuzcu et al., "Percutaneous valve procedures: an update," Current Problems in Cardiology, vol. 33, no. 8, pp. 417-457, 2008.

[22] A. Cribier, H. Eltchaninoff, C. Tron et al., "Early experience with percutaneous transcatheter implantation of heart valve prosthesis for the treatment of end-stage inoperable patients with calcific aortic stenosis," Journal of the American College of Cardiology, vol. 43, no. 4, pp. 698-703, 2004.

[23] J. G. Webb, M. Chandavimol, C. R. Thompson et al., "Percutaneous aortic valve implantation retrograde from the femoral artery," Circulation, vol. 113, no. 6, pp. 842-850, 2006.

[24] E. Grube, G. Schuler, L. Buellesfeld et al., "Percutaneous aortic valve replacement for severe aortic stenosis in highrisk patients using the second- and current third-generation self-expanding CoreValve prosthesis. Device success and 30day clinical outcome," Journal of the American College of Cardiology, vol. 50, no. 1, pp. 69-76, 2007.

[25] J. G. Webb, S. Pasupati, K. Humphries et al., "Percutaneous transarterial aortic valve replacement in selected high-risk patients with aortic stenosis," Circulation, vol. 116, no. 7, pp. 755-763, 2007.

[26] A. Cribier, H. Eltchaninoff, C. Tron et al., "Treatment of calcific aortic stenosis with the percutaneous heart valve: midterm follow-up from the initial feasibility studies: the French experience," Journal of the American College of Cardiology, vol. 47, no. 6, pp. 1214-1223, 2006.

[27] P. De Jaegere, L. C. Van Dijk, J. C. Laborde, et al., "True percutaneous implantation of the CoreValve aortic valve prosthesis by the combined use of ultrasound guided vascular access. Prostar XL and TandemHeart," Eurointervention, vol. 2, pp. 500-505, 2007.

[28] S. V. Lichtenstein, A. Cheung, J. Ye et al., "Transapical transcatheter aortic valve implantation in humans: initial clinical experience," Circulation, vol. 114, no. 6, pp. 591-596, 2006.

[29] T. Walther, V. Falk, M. A. Borger et al., "Minimally invasive transapical beating heart aortic valve implantation-proof of concept," European Journal of Cardio-Thoracic Surgery, vol. 31, no. 1, pp. 9-15, 2007.

[30] T. Walther, P. Simon, T. Dewey et al., "Transapical minimally invasive aortic valve implantation: multicenter experience," Circulation, vol. 116, no. 11, pp. I240-I245, 2007.

[31] C. Fraccaro, M. Napodano, G. Tarantini et al., "Expanding the eligibility for transcatheter aortic valve implantation. The trans-subclavian retrograde approach using the III generation CoreValve revalving system," Journal of the American College of Cardiology, vol. 2, no. 9, pp. 828-833, 2009.

[32] A. S. P. Sharp, I. Michev, and A. Colombo, "First trans-axillary implantation of Edwards Sapien valve to treat an incompetent aortic bioprosthesis," Catheterization and Cardiovascular Interventions, vol. 75, no. 4, pp. 507-510, 2010.
[33] G. Latsios, U. Gerckens, and E. Grube, "Transaortic transcatheter aortic valve implantation: a novel approach for the truly "no-access option" patients," Catheterization and Cardiovascular Interventions, vol. 75, no. 7, pp. 1129-1136, 2010.

[34] R. Bauernschmitt, C. Schreiber, S. Bleiziffer et al., "Transcatheter aortic valve implantation through the ascending aorta: an alternative option for no-access patients," The Heart Surgery Forum, vol. 12, no. 1, pp. E63-E64, 2009.

[35] F. Roques, S. A. M. Nashef, and P. Michel, "Risk factors for early mortality after valve surgery in Europe in the 1990s: lessons from the EuroSCORE pilot program," Journal of Heart Valve Disease, vol. 10, no. 5, pp. 572-578, 2001.

[36] L. F. Tops, D. A. Wood, V. Delgado et al., "Noninvasive evaluation of the aortic root with multislice computed tomography. Implications for transcatheter aortic valve replacement," Journal of the American College of Cardiology, vol. 1, no. 3, pp. 321-330, 2008.

[37] R. R. Moss, E. Ivens, S. Pasupati et al., "Role of echocardiography in percutaneous aortic valve implantation," Journal of the American College of Cardiology, vol. 1, no. 1, pp. 15-24, 2008.

[38] D. A. Wood, L. F. Tops, J. R. Mayo et al., "Role of multislice computed tomography in transcatheter aortic valve replacement," American Journal of Cardiology, vol. 103, no. 9, pp. 1295-1301, 2009.

[39] M. Akhtar, E. M. Tuzcu, S. R. Kapadia et al., "Aortic root morphology in patients undergoing percutaneous aortic valve replacement. Evidence of aortic root remodeling," Journal of Thoracic and Cardiovascular Surgery, vol. 137, no. 4, pp. 950956, 2009.

[40] P. Stolzmann, J. Knight, L. Desbiolles et al., "Remodelling of the aortic root in severe tricuspid aortic stenosis: implications for transcatheter aortic valve implantation," European Radiology, vol. 19, no. 6, pp. 1316-1323, 2009.

[41] V. Kurra, P. Schoenhagen, E. E. Roselli et al., "Prevalence of significant peripheral artery disease in patients evaluated for percutaneous aortic valve insertion: preprocedural assessment with multidetector computed tomography," Journal of Thoracic and Cardiovascular Surgery, vol. 137, no. 5, pp. 12581264, 2009.

[42] C. M. Otto, M. C. Mickel, J. W. Kennedy et al., "Threeyear outcome after balloon aortic valvuloplasty. Insights into prognosis of valvular aortic stenosis," Circulation, vol. 89, no. 2, pp. 642-650, 1994.

[43] N. Piazza, E. Grube, U. Gerckens et al., "Procedural and 30day outcomes following transcatheter aortic valve implantation using the third generation (18 Fr) CoreValve revalving systemml: results from the multicentre, expanded evaluation registry 1-year following CE mark approval," EuroIntervention, vol. 4, no. 2, pp. 242-249, 2008.

[44] J. Rodés-Cabau, J. G. Webb, A. Cheung et al., "Transcatheter aortic valve implantation for the treatment of severe symptomatic aortic stenosis in patients at very high or prohibitive surgical risk. Acute and late outcomes of the multicenter Canadian experience," Journal of the American College of Cardiology, vol. 55, no. 11, pp. 1080-1090, 2010.

[45] E. Grube, J. C. Laborde, U. Gerckens et al., "Percutaneous implantation of the CoreValve self-expanding valve prosthesis in high-risk patients with aortic valve disease: the Siegburg first-in-man study," Circulation, vol. 114, no. 15, pp. 16161624, 2006.

[46] M. Thomas, "30 day results of the SOURCE registry: a European registry of transcatheter aortic valve implantation 
using the Edwards SAPIEN ${ }^{\mathrm{TM}}$ valve," in Proceedings of the EuroPCR, Barcelona, Spain, May 2009.

[47] O. Wendler, T. Walther, and P. Nataf, "Trans-apical aortic valve implantation: univariate and multivariate analyses of the early results from the SOURCE registry," European Journal of Cardio-Thoracic Surgery .

[48] E. M. Flecher, J. W. Curry, T. M. Joudinaud, C. L. Kegel, P. A. Weber, and C. M. G. Duran, "Coronary flow obstruction in percutaneous aortic valve replacement. An in vitro study," European Journal of Cardio-Thoracic Surgery, vol. 32, no. 2, pp. 291-294, 2007.

[49] P. T. L. Chiam and C. E. Ruiz, "Percutaneous transcatheter aortic valve implantation: evolution of the technology," American Heart Journal, vol. 157, no. 2, pp. 229-242, 2009.

[50] G. Limongelli, V. Ducceschi, A. D’Andrea et al., "Risk factors for pacemaker implantation following aortic valve replacement: a single centre experience," Heart, vol. 89, no. 8, pp. 901-904, 2003.

[51] Z. El-Khally, B. Thibault, C. Staniloae et al., "Prognostic significance of newly acquired bundle branch block after aortic valve replacement," American Journal of Cardiology, vol. 94, no. 8, pp. 1008-1011, 2004.

[52] A. Sinhal, L. Altwegg, S. Pasupati et al., "Atrioventricular block after transcatheter balloon expandable aortic valve implantation," Journal of the American College of Cardiology, vol. 1, no. 3, pp. 305-309, 2008.

[53] N. Piazza, Y. Onuma, E. Jesserun et al., "Early and persistent intraventricular conduction abnormalities and requirements for pacemaking after percutaneous replacement of the aortic valve," Journal of the American College of Cardiology, vol. 1, no. 3, pp. 310-316, 2008.

[54] H. Jilaihawi, D. Chin, M. Vasa-Nicotera et al., "Predictors for permanent pacemaker requirement after transcatheter aortic valve implantation with the CoreValve bioprosthesis," American Heart Journal, vol. 157, no. 5, pp. 860-866, 2009.

[55] J. L. Quill, A. J. Hill, T. G. Laske, O. Alfieri, and P. A. Iaizzo, "Mitral leaflet anatomy revisited," Journal of Thoracic and Cardiovascular Surgery, vol. 137, no. 5, pp. 1077-1081, 2009.

[56] O. Alfieri, M. De Bonis, E. Lapenna et al., "'Edge-toedge" repair for anterior mitral leaflet prolapse," Seminars in Thoracic and Cardiovascular Surgery, vol. 16, no. 2, pp. 182187, 2004.

[57] O. Alfieri, F. Maisano, M. De Bonis et al., "The double-orifice technique in mitral valve repair: a simple solution for complex problems," Journal of Thoracic and Cardiovascular Surgery, vol. 122, no. 4, pp. 674-681, 2001.

[58] F. Maisano, L. Torracca, M. Oppizzi et al., "The edge-to-edge technique: a simplified method to correct mitral insufficiency," European Journal of Cardio-thoracic Surgery, vol. 13, no. 3, pp. 240-246, 1998.

[59] F. G. St. Goar, J. I. Fann, J. Komtebedde et al., "Endovascular edge-to-edge mitral valve repair: short-term results in a porcine model," Circulation, vol. 108, no. 16, pp. 1990-1993, 2003.

[60] G. P. Ussia, M. Barbanti, and C. Tamburino, "Feasibility of percutaneous transcatheter mitral valve repair with the MitraClip system using conscious sedation," Catheterization and Cardiovascular Interventions, vol. 75, no. 7, pp. 1137-1140, 2010.

[61] I. P. Casserly and S. R. Kapadia, "Advances in percutaneous valvular intervention," Expert Review of Cardiovascular Therapy, vol. 3, no. 1, pp. 143-158, 2005.

[62] F. E. Silvestry, L. L. Rodriguez, H. C. Herrmann et al., "Echocardiographic guidance and assessment of percutaneous repair for mitral regurgitation with the evalve MitraClip: lessons learned from EVEREST I," Journal of the American Society of Echocardiography, vol. 20, no. 10, pp. 1131-1140, 2007.

[63] T. Feldman, H. S. Wasserman, H. C. Herrmann et al., "Percutaneous mitral valve repair using the edge-to-edge technique: six-month results of the EVEREST phase I clinical trial," Journal of the American College of Cardiology, vol. 46, no. 11, pp. 2134-2140, 2005.

[64] T. Feldman, S. Kar, M. Rinaldi et al., "Percutaneous mitral repair with the MitraClip system. Safety and midterm durability in the initial EVEREST (Endovascular Valve Edge-toEdge REpair Study) cohort," Journal of the American College of Cardiology, vol. 54, no. 8, pp. 686-694, 2009.

[65] T. Feldman, Endovascular Valve Edge-to-Edge REpair Study (EVEREST II) Randomized Clinical Trial: Primary Safety and Efficacy Endpoints, American College of Cardiology, Atlanta, Ga, USA, 2010.

[66] J. G. Webb, J. Harnek, B. I. Munt et al., "Percutaneous transvenous mitral annuloplasty: initial human experience with device implantation in the coronary sinus," Circulation, vol. 113, no. 6, pp. 851-855, 2006.

[67] J. R. Liddicoat, B. D. Mac Neill, A. M. Gillinov et al., "Percutaneous mitral valve repair: a feasibility study in an ovine model of acute ischemic mitral regurgitation," Catheterization and Cardiovascular Interventions, vol. 60, no. 3, pp. 410-416, 2003.

[68] C. V. Maniu, J. B. Patel, D. G. Reuter et al., "Acute and chronic reduction of functional mitral regurgitation in experimental heart failure by percutaneous mitral annuloplasty," Journal of the American College of Cardiology, vol. 44, no. 8, pp. 16521661, 2004.

[69] J. Schofer, T. Siminiak, M. Haude et al., "Percutaneous mitral annuloplasty for functional mitral regurgitation: results of the CARILLON mitral annuloplasty device european union study," Circulation, vol. 120, no. 4, pp. 326-333, 2009.

[70] T. Siminiak, U. C. Hoppe, J. Schofer et al., "Effectiveness and safety of percutaneous coronary sinus-based mitral valve repair in patients with dilated cardiomyopathy (from the AMADEUS trial)," American Journal of Cardiology, vol. 104, no. 4, pp. 565-570, 2009.

[71] K. Fukamachi, M. Inoue, Z. B. Popović et al., "Off-pump mitral valve repair using the Coapsys device: a pilot study in a pacing-induced mitral regurgitation model," Annals of Thoracic Surgery, vol. 77, no. 2, pp. 688-692, 2004.

[72] Y. K. Mishra, S. Mittal, P. Jaguri, and N. Trehan, "Coapsys mitral annuloplasty for chronic functional ischemic mitral regurgitation: 1-year results," Annals of Thoracic Surgery, vol. 81, no. 1, pp. 42-46, 2006.

[73] E. A. Grossi, P. C. Saunders, Y. J. Woo et al., "Intraoperative effects of the Coapsys annuloplasty system in a randomized evaluation (RESTOR-MV) of functional ischemic mitral regurgitation," Annals of Thoracic Surgery, vol. 80, no. 5, pp. 1706-1711, 2005.

[74] W. R. Pedersen, P. Block, M. Leon et al., "iCoapsys mitral valve repair systemml: percutaneous implantation in an animal model," Catheterization and Cardiovascular Interventions, vol. 72, no. 1, pp. 125-131, 2008.

[75] G. E. Pate, A. Al Zubaidi, M. Chandavimol, C. R. Thompson, B. I. Munt, and J. G. Webb, "Percutaneous closure of prosthetic paravalvular leaks: case series and review," Catheterization and Cardiovascular Interventions, vol. 68, no. 4, pp. 528-533, 2006.

[76] T. C. Aranzulla, J. Cosgrave, G. La Canna et al., "Percutaneous treatment of periprosthetic mitral valve leaks: is it just a futile 
exercise?" Annals of Thoracic Surgery, vol. 86, no. 3, pp. 996998, 2008.

[77] M. S. Kim, I. P. Casserly, J. A. Garcia, A. J. Klein, E. E. Salcedo, and J. D. Carroll, "Percutaneous transcatheter closure of prosthetic mitral paravalvular leaks. Are we there yet?" Journal of the American College of Cardiology, vol. 2, no. 2, pp. 81-90, 2009.

[78] S. K. Bhudia, P. M. McCarthy, N. G. Smedira, B.-K. Lam, J. Rajeswaran, and E. H. Blackstone, "Edge-to-edge (Alfieri) mitral repair: results in diverse clinical settings," Annals of Thoracic Surgery, vol. 77, no. 5, pp. 1598-1606, 2004.

[79] A. R. Kherani, F. H. Cheema, J. Casher et al., "Edge-to-edge mitral valve repair: the Columbia Presbyterian experience," Annals of Thoracic Surgery, vol. 78, no. 1, pp. 73-76, 2004.

[80] F. Maisano, A. Caldarola, A. Blasio et al., "Midterm results of edge-to-edge mitral valve repair without annuloplasty," Journal of Thoracic and Cardiovascular Surgery, vol. 126, no. 6, pp. 1987-1997, 2003.

[81] S. Privitera, J. Butany, R. J. Cusimano, C. Silversides, H. Ross, and R. Leask, "Images in cardiovascular medicine. Alfieri mitral valve repair: clinical outcome and pathology," Circulation, vol. 106, no. 21, pp. e173-e174, 2002.

[82] J. I. Fann, F. G. St. Goar, J. Komtebedde et al., "Beating heart catheter-based edge-to-edge mitral valve procedure in a porcine model: efficacy and healing response," Circulation, vol. 110, no. 8, pp. 988-993, 2004. 


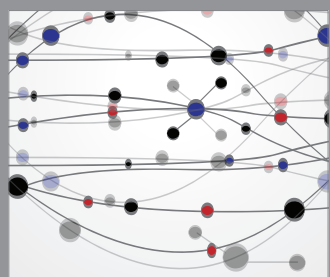

The Scientific World Journal
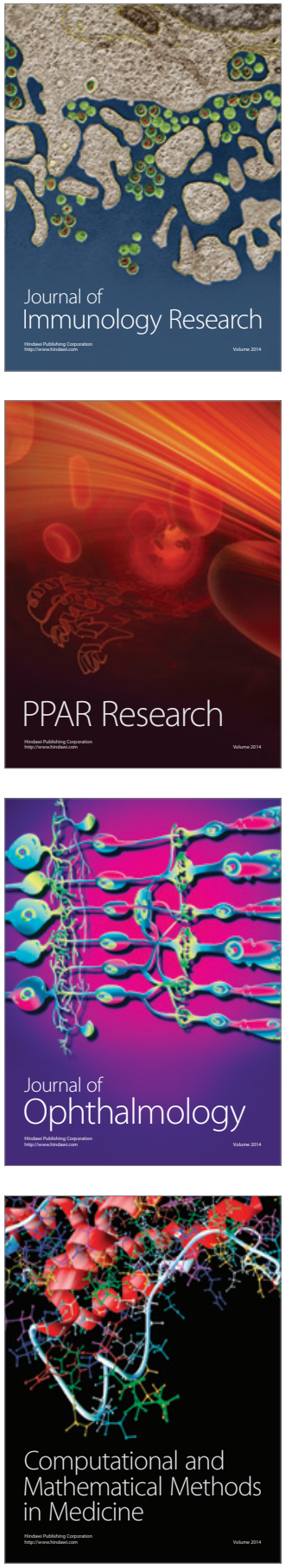

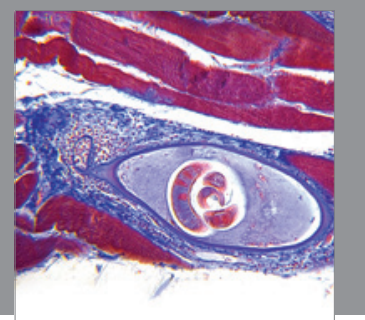

Gastroenterology

Research and Practice
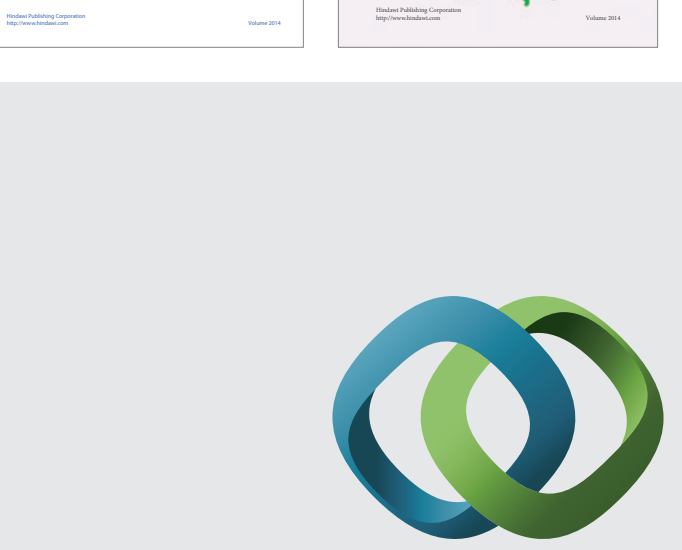

\section{Hindawi}

Submit your manuscripts at

http://www.hindawi.com
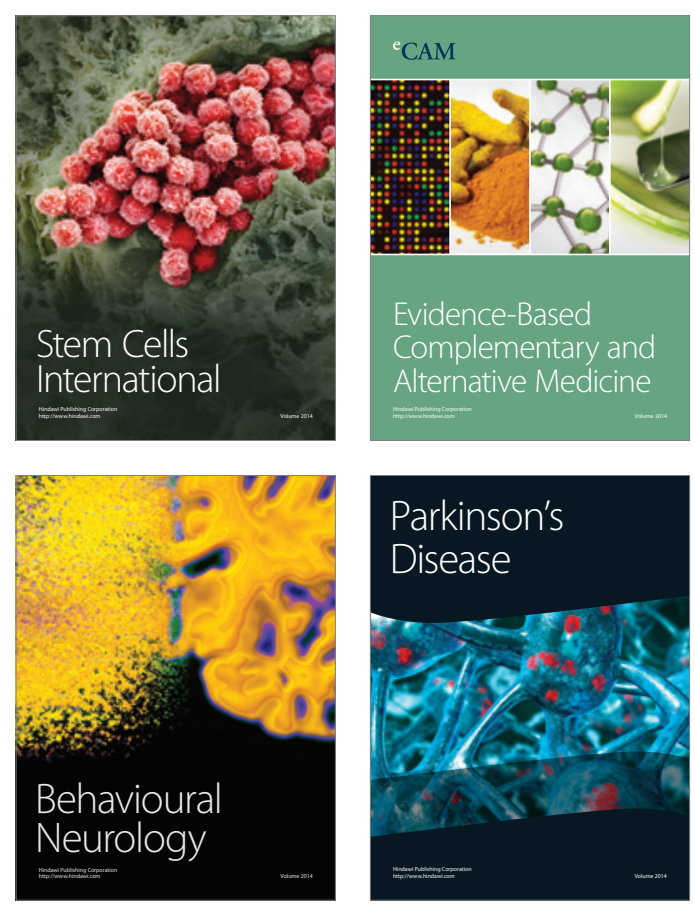

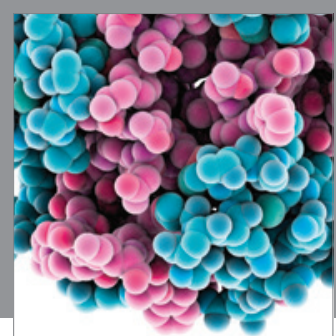

Journal of
Diabetes Research

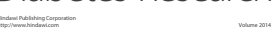

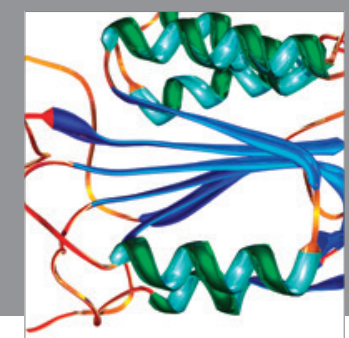

Disease Markers
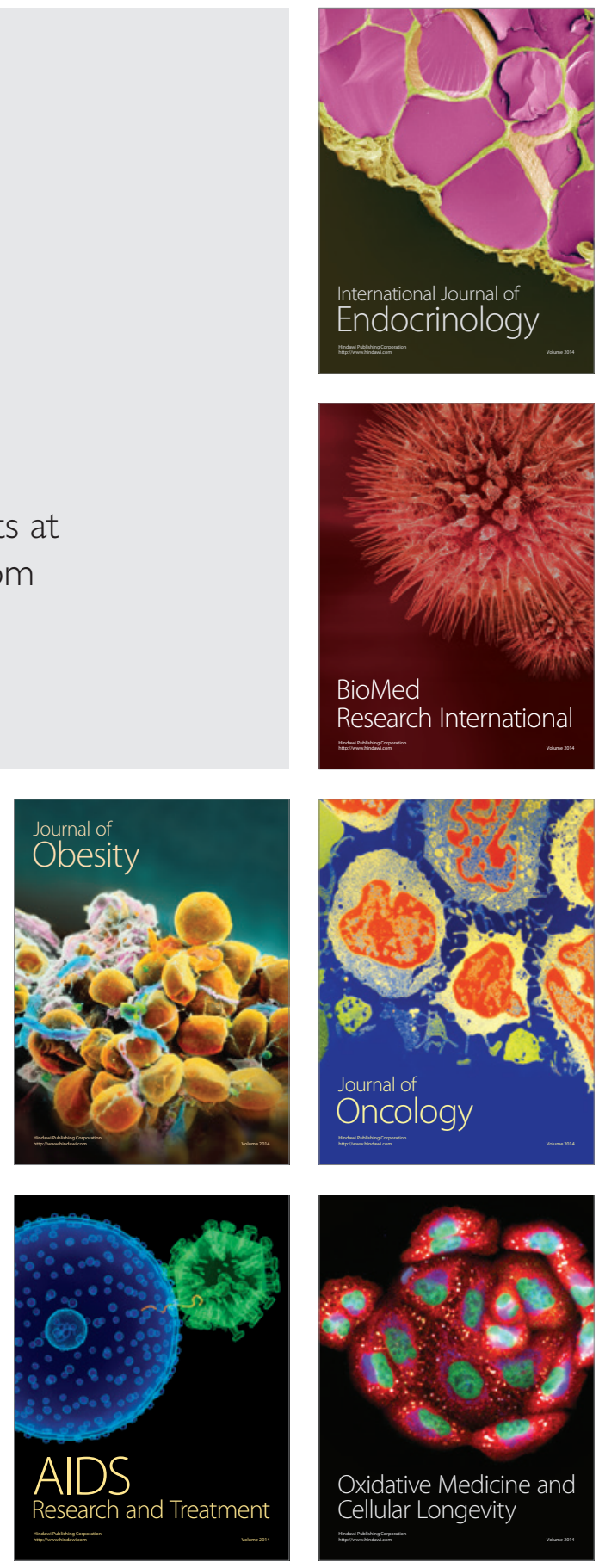